\title{
PENGARUH KEADILAN ORGANISASI DAN PERCEIVED ORGANIZATIONAL SUPPORT (POS) TERHADAP PERILAKU KONTRAPRODUKTIF GURU SD NEGERI DI KECAMATAN BEJI KOTA DEPOK PROVINSI JAWA BARAT
}

\author{
Indah Wijayanti ${ }^{1}$
}

\begin{abstract}
The purpose of this research is to comprehensively understand about the effects of organizational justice and perceived organizational support (POS) on counterproductive work behavior. The research has been conducted at elementary state schools in Depok, West Java. The research methodology used was a survey method with data analysis of path analysis. The respondents were 107 out of 146 total teachers which were selected at a simple random way. Analysis and interpretation of the data indicate that: (1). Organizational justice has a negative direct effect of on the counterproductive work behavior. (2). Perceived organizational support (POS) has a negative direct effect on the counterproductive work behavior, and (3). Organizational justice has a positive direct effect on the perceived organizational support (POS).
\end{abstract}

Keywords: organizational justice, perceived organizational support (POS). counterproductive work behavior.

\section{PENDAHULUAN}

Pendidikan merupakan sarana untuk memajukan dan menentukan kualitas suatu bangsa. Bahkan hal ini juga menentukan kelangsungan hidup dan daya saing bangsa. Sebuah pembelajaran tentang arti penting pendidikan adalah bangsa Jepang pasca pemboman dengan bom atom di Hiroshima dan Nagasaki yang meluluhlantakkan persendian ekonomi dan kehidupan bangsa Jepang pada Perang Dunia II. Kaisar Jepang saat itu langsung memerintahkan pendataan kembali guru-guru Jepang yang tersisa, dan bukan pendataan kekuatan ekonomi apalagi militer. Hasilnya, bangsa Jepang kembali segera bangkit dan menjadi pesaing utama dunia untuk segala bidang. Sebuah fenomena peningkatan kualitas Sumber Daya Manusia suatu negara yang sangat mengilhami dunia terutama dunia pendidikan.

Keunggulan sekolah terletak pada proses pendidikan dimana SDM sebagai salah satu factor penentu kualitas proses yang menghasilkan output pendidikan. Ouput pendidikan berupa mutu lulusan, prestasi sekolah hingga kemajuan sekolah adalah tujuan-tujuan yang harus dicapai sekolah. Banyaknya sekolah dan SDM di sekolah terutama Sekolah Dasar Negeri yang terungkap melakukan kebijakan dan tindakan yang tidak semestinya dalam meningkatkan mutu lulusan peserta didik seperti

\footnotetext{
${ }^{1}$ School Owner dan Bimbel, Jakarta
} 
kecurangan saat Ujian Nasional. Demi nama baik dan tanggung jawab terhadap orang tua murid, pihak sekolah atau oknum guru melakukan kecurangan tersebut.

Tindakan atau perilaku yang tidak mencerminkan perilaku baik atau bahkan mengingkari dan membahayakan tujuan organisasi dapat digolongkan kedalam perilaku kontraproduktif (Contraproductive Work Behavior/CWB). Selain melakukan kecurangan seperti diatas, walaupun terkesan memenuhi target kualitas dan mutu lulusan, perilaku kontraproduktif juga memiliki ciri-ciri menyakiti dan menfitnah orang lain, membahayakan, lari dari tanggung jawab, sabotase kerja dan melakukan kecurangan seperti korupsi atau pencurian.

Perilaku kontraproduktif yang terjadi di antara guru-guru Sekolah Dasar Negeri Kota Depok bisa menimbulkan efek yang kurang menguntungkan untuk sebuah organisasi yakni sekolah atau bahkan untuk peserta didik dan orang tua peserta didik. Perilaku kontraproduktif tidak dapat dianggap remeh karena perilaku ini dapat memperburuk kinerja organisasi dan menghambat organisasi dalam pencapaian tujuannya.

Perilaku kontraproduktif guru dalam pendidikan akan menghambat peningkatan mutu dan memberi dampak pada penurunan kualitas sumber daya manusia oleh karena itu masalah perilaku kontraproduktif guru dalam pendidikan maupun pembelajaran harus mendapat perhatian serius dari semua pihak yaitu dengan menggali faktor-faktor yang mempengaruhi perilaku kontraproduktif.

\section{Perilaku kontraproduktif.}

Schemerhon Hunt dan Osborn (2010:74) menjelaskan perilaku kontraproduktif dengan "counterproductive work behaviors intentionally disrupt relationships or performance at work." Perilaku kontra produktif disengaja mengganggu hubungan atau kinerja saat bekerja. Hal tersebut dijelaskan oleh Kreitner dan Knicki (2010:74), "these costly behavior known as counterproductive work behaviors (CWBs), types of behavior that harm employees and the organization as a whole." Perilaku merugikan ini dikenal dengan perilaku kontraproduktif (CWBs), jenis-jenis perilaku yang membahayakan para pekerja dan organisasi secara keseluruhan.

Menurut Steve H. Jex (2002:146), "counterproductive behavior defined as behavior that explicitly runs counter to the goals of an organization." Perilaku kontraproduktif dijelaskan sebagai perilaku yang terjadi nyata berlawanan dengan tujuan organisasi. McShane dan Von Glinow (2010:18) menyatakan, "CWBs are voluntary behaviors that have the potential to directly or indirectly harm the organization." CWBs adalah perilaku sukarela yang memiliki potensi secara langsung maupun tidak langsung membahayakan organisasi.

Banyak bentuk perilaku kontraproduktif yang terjadi dalam suatu organisasi. Bentuk perilaku kontraproduktif menurut Robbins dan Coulter (2012:402) yakni, "workplace misbehavior shows up in organization in four ways: deviance, aggression, antisocial behavior, and violence." Perilaku buruk tempat kerja berwujud dalam empat cara: perilaku menyimpang, penyerangan, perilaku antisosial, dan kejahatan. 
Selanjutnya menurut McShane dan Von Glinow (2010:18) menjelaskan beberapa bentuk perilaku kontra produktif (yaitu: "they include abuse of others (e.g., insults and nasty comments), threats (threatening harm), work avoidance (e.g., tardiness), work sabotage (doing work incorrectly), and over acts (theft). Perilaku CWB ini mencakup tindakan kasar kepada orang lain (seperti pernyataan menghina dan tidak menyenangkan), ancaman (yang membahayakan), kemangkiran kerja (keterlambatan/ketidakhadiran), sabotase kerja (melakukan pekerjaan tidak sesuai prosedur), dan perilaku parah (pencurian).

Menurut Steve H. Jex (2002:147), bentuk-bentuk perilaku kontraproduktif ini antara lain: ineffective job performance, employee absenteeism, employee turnover, accidents, employee theft, workplace violence, substance abuse, dan sexual harassment." Hasil kerja yang tidak efektif, ketidakhadiran karyawan, pergantian karyawan, kecelakaan, pencurian, penyimpangan perilaku kerja, penyalahgunaan zat terlarang, dan pelecehan seksual.

Dari konsep yang telah dideskripsikan di atas dapat disintesiskan bahwa perilaku kontraproduktif adalah perilaku sengaja anggota organisasi yang mengancam kinerja organisasi dan memiliki potensi membahayakan individu dan organisasi secara keseluruhan dalam mencapai tujuan organisasi dengan indikator sabotase, penyalahgunaan, pelecehan, dan ancaman.

\section{Perceived Organizational Support (POS)}

Istilah Perceived Organizational Support (POS) diperjelas dengan pendapat Robbins dan Coulter (2012:405), "perceived organizational support are employees' general belief that their organization values their contribution and cares about their well-being." Persepsi dukungan organisasi adalah perasaan percaya secara menyeluruh bahwa organisasi mereka menghargai kontribusi pekerja dan peduli terhadap kesejahteraan pekerja.

Senada dengan di atas, Robbins dan Judge (2011:112) mengungkapkan: "Perceived organizational support (POS) is the degree to which employees believe the organization values their contribution and cares about their well-being (for example, an employee believes his organizational would accommodate him if he had a child-care problem or would forgive an honest mistake on his part). Persepsi dukungan organisasi (POS) adalah tingkat kepercayaan karyawan bahwa organisasi menghargai kontribusi karyawan dan peduli dengan kesejahteraan mereka (sebagai contoh, seorang karyawan percaya organisasinya akan menolongnya jika dia memiliki masalah pengasuhan anak atau akan memaafkan kesalahan yang diakui karena kelalaiannya).

Menurut Allen dkk., dalam Ulker Colakoglu dkk., (2010:125-150) menyatakan, "perceived organisational support is also defined as "how much the organization values employees' contributions and cares about them." Persepsi dukungan organisasi didefinisikan sejauh mana organisasi menghargai kontribusi para karyawan dan peduli terhadap mereka. Menurut Eisenberger dkk., (2002) ada empat bentuk umum bentuk perlakuan baik yang diberikan oleh organisasi kepada karyawannya, yakni: "fairness, supervisor support, organizational rewards dan job conditions." 
Berdasarkan deskripsi konsep di atas dapat disintesiskan bahwa efikasi diri adalah persepsi dukungan organisasi (POS) adalah perasaan seseorang terhadap organisasi dalam mendukung dan memperlakukan karyawan dengan baik, dengan indikator: dukungan atasan, penghargaan organisasi, dan kondisi kerja.

\section{Keadilan Organisasi}

Cakupan keadilan organisasi cukup luas, pembahasan mengenai hal ini dapat dipahami dengan baik seperti pendapat Gibson dkk., (2012:148), "organizational justice is the degree to which individuals feel fairly treated within the organizations for which they work." Keadilan organisasi adalah tingkat dimana individu merasa diperlakukan dengan adil dalam organisasi dimana mereka bekerja.

Luthans (2011:183) menetapkan tiga dimensi dalam keadilan organisasi, yaitu: Distributive justice, which is an individual's cognitive evaluation regarding whether or not the amounts and allocations of rewards in a social setting are fair. Procedural justice is concerned with the fairness of the procedure used to make a decision. Whereas procedural justice is the exchange between the employee and the employing organization, interactional justice is between individuals (e.g. the employee and the supervisor). Keadilan distribusi, adalah penilaian pendapat pribadi mengenai adil atau tidaknya jumlah dan ketentuan imbalan di lingkup sosial. Keadilan prosedural terkait dengan keadilan tata cara yang digunakan untuk menentukan kebijakan. Keadilan prosedural adalah keterkaitan antara pekerja dan yang memperkerjakan, sedangkan keadilan interaksional diantara individual (seperti pekerja dan atasan).

Berdasarkan deskripsi konsep di atas dapat disintesiskan bahwa keadilan organisasi adalah perlakuan adil atau tidak adil yang dirasakan oleh para anggota organisasi pada segala bentuk perlakuan yang ada di dalam organisasi, dengan indikiator: keadilan distribusi (kelayakan upah, kesempatan promosi, dan kesetaraan), keadilan prosedural (kesempatan mengemukakan pendapat, keterwakilan, dan kejelasan), keadilan interaksional (perhatian, saling menghormati dan kesopanan).

\section{METODE}

Penelitian ini dilaksanakan dengan menggunakan pendekatan kuantitatif, jenis asosiatif kausal metode survey dan teknik analisis jalur (path analysis). Penelitian ini dilakukan tiga bulan yaitu mulai bulan Maret sampai dengan bulan Mei 2014. Penelitian dilaksanakan di SD negeri yang berada di 1 (satu) Kecamatan Kabupaten Seluma. Populasi terjangkau pada penelitian ini sejumlah 149 orang guru. Sampel penelitian sebanyak 107 orang. Analisa data untuk pengujian hipotesis akan dilakukan dengan menggunakan analisis jalur, yaitu teknik yang diterapkan untuk menjelaskan pengaruh antara variabel-variabel penelitian. Sebelum dilaksanakan analisis jalur, uji signifikansi regresi dan uji linearitas regresi sebagai prasayarat uji statistik dilakukan uji normalitas galat taksiran dari masing-masing variabel penelitian dengan Uji-Liliefors, Statistik inferensial digunakan untuk menguji hipotesis tentang pengaruh antar variabel dengan menggunakan analisis jalur. 


\section{HASIL DAN PEMBAHASAN}

\section{Pengaruh Keadilan Organisasi terhadap Perilaku Kontraproduktif}

Hasil analisis korelasi sederhana antara keadilan organisasi dengan perilaku kontraproduktif memperoleh koefisien korelasi sebesar $\mathrm{r}_{13}-0,769$ dan koefisien jalur $\rho_{31}$ -0,3950. Dengan demikian pengaruh keadilan organisasi terhadap perilaku kontraproduktif cukup tinggi atau negatif, artinya keadilan organisasi yang adil akan menurunkan perilaku kontraproduktif guru SD Negeri di Kota Depok.

Temuan penelitian ini relevan dengan sebuah teori yang dikemukakan oleh Quick dan Nelson (2013:116) melalui Principles of Organizational Behavior: Realities and Challengges $8^{\text {th }} \mathrm{Ed}$. Teori tersebut menjelaskan bahwa, "unfairness at work is a major cause of deviance, sabotage and retaliation." Ketidakadilan dalam kerja adalah penyebab utama perilaku merugikan, sabotase dan pembalasan dendam. Ketidakadlian organisasi bisa berakibat beberapa tindakan yang lebih merugikan meskipun pada kelihatannya para karyawan tetap bekerja tetapi merasakan bahwa prosedur yang digunakan untuk memutuskan pemutusan kerja tidak adil, perilaku negatif seperti mengumpat atasan atau balas dendam bisa terjadi.

Begitu kuatnya pengaruh keadilan organisasi melalui salah satu indikatornya yakni keadilan prosedural terhadap perilaku kontraproduktif dipaparkan oleh McShane dan Von Glinow (2010:147) dalam Organizational behavior: Emerging knowledge and practice for the real world menyatakan bahwa, "Procedural justice has a strong influence on a person's emotions and motivation. Employees tend to experience anger toward the source of injustice, which generates various response behaviors that scholars categorize as either withdrawal or aggression. Employees also engage in these counterproductive behaviors to educate the decision maker, thereby trying to minimize the likelihood of future injustices." Keadilan prosedural memiliki pengaruh yang kuat terhadap emosi dan motivasi seseorang. Karyawan cenderung merasa amarah terhadap sumber ketidakadilan, yang akan meningkatkan respon perilaku bermacam-macam yang para ahli menyebutnya sebagai pengunduran diri atau penyerangan. Karyawan yang terlibat perilaku kontraproduktif ini bertujuan untuk memberitahu para pembuat keputusan, dengan demikian atasan akan berusaha menekan kemungkinan ketidakadilan di masa mendatang. Steve H. Jex (2002:146) menjelaskan, "counterproductive behavior defined as behavior that explicitly runs counter to the goals of an organization." Perilaku kontraproduktif dijelaskan sebagai perilaku yang terjadi nyata berlawanan dengan tujuan organisasi. McShane dan Von Glinow (2010:18) menyatakan, "CWBs are voluntary behaviors that have the potential to directly or indirectly harm the organization." CWBs adalah perilaku sukarela yang memiliki potensi secara langsung maupun tidak langsung membahayakan organisasi. Bentuk perilaku kontraproduktif menurut Robbins dan Coulter (2012:402) yakni, "workplace misbehavior shows up in organization in four ways: deviance, aggression, antisocial behavior, and violence." Perilaku buruk tempat kerja berwujud dalam empat cara: perilaku menyimpang, penyerangan, perilaku antisosial, dan kejahatan. Selanjutnya menurut McShane dan 
Von Glinow (2010:18) menjelaskan beberapa bentuk perilaku kontra produktif (yaitu: "they include abuse of others (e.g., insults and nasty comments), threats (threatening harm), work avoidance (e.g., tardiness), work sabotage (doing work incorrectly), and over acts (theft). Perilaku CWB ini mencakup tindakan kasar kepada orang lain (seperti pernyataan menghina dan tidak menyenangkan), ancaman (yang membahayakan), kemangkiran kerja (keterlambatan/ketidakhadiran), sabotase kerja (melakukan pekerjaan tidak sesuai prosedur), dan perilaku parah (pencurian).

Pendapat kedua ahli di atas memberikan pemahaman bahwa keadilan organisasi memiliki pengaruh langsung terhadap perilaku kontraproduktif. Dengan demikian hasil penelitian menunjukan bahwa terdapat pengaruh positif keadilan organisasi terhadap perilaku kontraproduktif.

\section{Pengaruh Perceived Organizational Support (POS) Terhadap Perilaku Kontraproduktif}

Hasil analisis korelasi sederhana antara Perceived Organizational Su pport (POS) dengan perilaku kontraproduktif memperoleh koefisien korelasi sebesar $r_{23}=-0,793$ dan koefisien jalur $\rho_{32}=-0,4951$. Dengan demikian pengaruh Perceived Organizational Support (POS terhadap perilaku kontraproduktif cukup tinggi atau negatif, artinya peningkatan Perceived Organizational Support (POS) akan menurunkan perilaku kontraproduktif guru SD Negeri di Kota Depok.

Temuan penelitian ini relevan dengan teori yang dikemukakan oleh Robbins dan Judge (2012:112) dalam Organizational Behavior 14th Ed. yang menyatakan bahwa, "research suggest employees with strong POS perceptions are more likely to have lower tardiness." Penelitian menyarankan pekerja dengan persepsi dukungan organisasi yang kuat akan lebih memiliki keterlambatan kerja yang rendah.

Dampak POS mencakup berbagai topik perilaku organisasi seperti pemilihan perilaku baik (lawan dari perilaku kontraproduktif), pengembangan karir, pelatihan karyawan baru, dan desain kerja/pengayaan kerja. Pendapat Sarah Kay Nielsen (2006:356) dalam A Multi Source Model of Perceived Organizational Support and Performance menyatakan, "present findings add to this literature and suggest that not only is POS a strong predictor of positive work behavior, but it is also a strong predictor of employees' active negative work behaviors." Penemuan terkini menambah literature dan menyatakan bahwa tidak hanya persepsi dukungan organisasi (POS) memiliki pengaruh kuat terhadap perilaku kerja baik, tetapi juga memilki pengaruh kuat terhadap perilaku kerja tidak baik (kontraproduktif). Pendapat ini lebih menegaskan POS memiliki dampak kuat pada berbagai model perilaku kontraproduktif. Robbins dan Judge (2011:112) mengungkapkan: "Perceived organizational support (POS) is the degree to which employees believe the organization values their contribution and cares about their well-being (for example, an employee believes his organizational would accommodate him if he had a child-care problem or would forgive an honest mistake on his part). Persepsi dukungan organisasi (POS) adalah tingkat kepercayaan karyawan bahwa organisasi menghargai kontribusi karyawan dan 
peduli dengan kesejahteraan mereka (sebagai contoh, seorang karyawan percaya organisasinya akan menolongnya jika dia memiliki masalah pengasuhan anak atau akan memaafkan kesalahan yang diakui karena kelalaiannya). Allen dkk., dalam Ulker Colakoglu dkk., (2010:125-150) menyatakan, "perceived organisational support is also defined as "how much the organization values employees' contributions and cares about them." Persepsi dukungan organisasi didefinisikan sejauh mana organisasi menghargai kontribusi para karyawan dan peduli terhadap mereka. Dengan demikian hasil penelitian menunjukan bahwa terdapat pengaruh negatif POS terhadap perilaku kontraproduktif.

\section{Pengaruh Keadilan Organisasi Terhadap Perceived Organizational Support (POS)}

Hasil analisis korelasi sederhana antara keadilan organisasi dengan POS memperoleh koefisien korelasi sebesar $r_{12}=0,755$ dan koefisien jalur $\rho_{21}=0,755$. Dengan demikian pengaruh keadilan organisasi terhadap POS cukup tinggi atau positif, artinya keadilan organisasi yang adil akan meningkatkan POS guru SD Negeri di Kota Depok.

Temuan penelitian ini relevan dengan teori yang dikemukakan oleh Luthans (2011:150) dalam Organizational Behavior: An evidence Based Approach yang menyatakan bahwa, "it seems that procedural justice affects employees by influencing their perceived organizational support." Kelihatannya keadilan prosedural mempengaruhi karyawan dengan mempengaruhi persepsi dukungan organisasi mereka (POS).

Keadilan yang ditata dalam sebuah organisasi dapat merangsang individu untuk pencapaian kinerja yang tinggi dan kinerja yang tinggi tidak lepas dari peran persepsi dukungan org Gibson dkk., (2012:148), "organizational justice is the degree to which individuals feel fairly treated within the organizations for which they work." Keadilan organisasi adalah tingkat dimana individu merasa diperlakukan dengan adil dalam organisasi dimana mereka bekerja. Luthans (2011:183) menetapkan tiga dimensi dalam keadilan organisasi, yaitu: Distributive justice, which is an individual's cognitive evaluation regarding whether or not the amounts and allocations of rewards in a social setting are fair. Procedural justice is concerned with the fairness of the procedure used to make a decision. Whereas procedural justice is the exchange between the employee and the employing organization, interactional justice is between individuals (e.g. the employee and the supervisor). Keadilan distribusi, adalah penilaian pendapat pribadi mengenai adil atau tidaknya jumlah dan ketentuan imbalan di lingkup sosial. Keadilan prosedural terkait dengan keadilan tata cara yang digunakan untuk menentukan kebijakan. Keadilan prosedural adalah keterkaitan antara pekerja dan yang memperkerjakan, sedangkan keadilan interaksional diantara individual (seperti pekerja dan atasan).

Shore dan Shore (2009:526) dalam tulisannya yang berjudul Perceived Organizational Support and Organizational Justice menyatakan bahwa, "second, although the distributive and procedural justice of decisions should influence POS." Kedua, meskipun keputusan keadilan distribusi dan prosedural pasti mempengaruhi dukungan organisasi (POS). Gibson dkk., (2012:148), “organizational justice is the degree to which 
individuals feel fairly treated within the organizations for which they work." Keadilan organisasi adalah tingkat dimana individu merasa diperlakukan dengan adil dalam organisasi dimana mereka bekerja. Dengan demikian hasil penelitian menunjukan bahwa terdapat pengaruh positif keadilan organisasi terhadap POS.

\section{PENUTUP}

Kesimpulan: Berdasarkan hasil analisa dan kajian dari penelitian ini dapat disimpulkan bahwa: (1) Keadilan organisasi berpengaruh langsung negatif terhadap perilaku kontraproduktif. Ini berarti bahwa keadilan organisasi yang adil akan menurunkan perilaku kontraproduktif guru SD Negeri di Kecamatan Beji Kota Depok. (2) Perceived organizational support (POS) berpengaruh langsung negatif terhadap perilaku kontraproduktif. Ini berarti bahwa peningkatan perceived organizational support (POS) akan menurunkan perilaku kontraproduktif guru SD Negeri di Kecamatan Beji Kota Depok. (3) Keadilan organisasi berpengaruh langsung positif terhadap perceived organizational support (POS). Ini berarti bahwa keadilan organisasi yang adil akan meningkatkan perceived organizational support (POS) guru SD Negeri di Kecamatan Beji Kota Depok.

Saran: Berdasarkan kesimpulan hasil penelitian di atas dapat disampaikan saran-saran praktis tentang keadilan organisasi yang sesuai dan peningkatan perceived organizational support (POS) dalam rangka menurunkan perilaku kontraproduktif guru SD negeri sebagai berikut: (1) Bagi Dinas Pendidikan Kota Depok hendaknya membuka kesempatan bagi guru untuk melakukan pengembangan kompetensi guru dengan merata-adilkan kesempatan mengikuti berbagai macam pendidikan dan pelatihan, seminar, workshop dan kegiatan lainnya sehingga guru selalu dapat berkembang dan belajar serta mendapatkan pengetahuan dan ketrampilan yang bermanfaat bagi pengembangan karirnya. Kegiatan tersebut diharapkan akan meningkatkan perspsi dukungan organisasi yang pada akhirnya dapat mendorong guru untuk tidak melakukan perilaku kontraproduktif dalam pembelajaran (2) Bagi Kepala Sekolah sistem keadilan organisasi yang diterapkan di sekolah yang diimplementasikan saat ini perlu ditinjau dan dibenahi agar memiliki manfaat optimal bagi penekan perilaku kontraproduktif guru. Pembenahan dapat dimulai dengan melakukan evaluasi terhadap sistem keadilan organisasi yang telah diimplementasikan, baik terkait dengan pertimbangan-pertimbangan yang dijadikan tolak ukur dalam menetapkan keadilan prosedural, keadilan distribusi, maupun keadilan interaksional yang akan diberikan. (3) Bagi para guru SD Negeri di Kota Depok perlu meningkatkan persepsi terhadap dukungan organisasi kepada para guru (POS), karena dengan POS yang tinggi seorang guru merasa yakin dengan kemampuan yang dimillikinya untuk dapat menyelesaikan tugasnya dengan baik dan mampu mengatasi tantangan maupun persoalan yang dihadapi dalam pekerjaan. Bagi para peneliti lain agar penelitian ini dapat dijadikan rujukan dalam penelitian lanjutan terkait dengan perilaku kontraproduktif guru karena 
penelitian ini hanya terbatas pada keadilan organisasi dan perceived organizational support (POS) atau persepsi dukungan organisasi guru saja. 


\section{DAFTAR RUJUKAN}

Colakoglu, Ulker, Osman Culha dan Hakan Atay, The Effects of Perceived Organizational Support on employees' Affective Outcomes: Evidence from the Hotel Industry. Tourism and Hospitality Management, Vol. 16, No. 2, 2010.

Gibson, James L., et., al., Organizations: Behavior, Structure, Process (New York: McGraw Hill Co., 2012).

Jex, Steve H., Organizational Psychology: A Scientist-Practitioner Approach. New York: John Wiley \& Sons, 2002.

Kreitner dan Knicki, Organizational Behavior 9th Ed. New York: McGraw Hill/Irwin, 2010.

Luthans, Fred, Organizational Behavior: An evidence Based Approach. New York: McGrawHill/Irwin, 2011.

McShane, Steven L., dan Mary Ann Von Glinow, Organizational behavior: Emerging knowledge and practice for the real world. New York: McGraw-Hill/Irwin, 2010.

Nielsen, Sarah Kay, A Multi Source Model of Perceived Organizational Support and Performance. University of Tennessee, 2006.

Quick, James Campbell, dan Debra L. Nelson, Principles of Organizational Behavior: Realities and Challengges $8^{\text {th }}$ Ed. China: South Western, Cengage Learning, 2013.

Robbins, Stephen P., dan Mary Coulter, Management. Upper Saddle River - New Jersey: Prentice Hall, 2012.

Robbins, Stephen P., dan Timothy A. Judge, Organizational Behavior 14th Ed. New Jersey: Pearson Education Inc., 2011.

Schemerhon, Jhon R., et. al., Organizational Behavior 11 th Ed. USA: Jhon Wiley \& Sons, Inc., 2010.

Shore, Lynn McFarlane dan Ted H. Shore, Perceived Organizational Support and Organizational Justice,

www.rohan.sdsu.edu/ lshore/reprints_pdf/perceived_organizational_suppor t_and_org_justice. 2009. 